\title{
Memórias sobre os cuidados: a tuberculose e o modelo sanatorial no início do século passado
}

\author{
Memories on the cares: the tuberculosis and \\ modelo sanatorial at the beginning of the last century
}

Cristiane P. C. Lacaz

Enfermeira e professora-doutora da UFRJ em lotação no ITA

cristianelacaz@uol.com.br

Lúcia Pedroso da Cruz

Bióloga e doutoranda da Faculdade de Educação da Unicamp

\section{Maria Helena S. Bagnato}

Enfermeira e professora doutora da Faculdade de Educação da Unicamp

\section{Resumo}

Pesquisa de natureza qualitativa que se propõe a descrever a atuação de personagens que cuidavam dos pacientes reclusos no Sanatório Vicentina Aranha, no início do século passado. O primeiro sanatório de São José dos Campos foi inaugurado em 1924, sob a direção da Irmandade da Santa Casa de Misericórdia de São Paulo e recebeu o nome de Vicentina Aranha. O presente estudo elegeu como método de pesquisa, para coleta e análise dos dados, a história oral. Por meio das entrevistas, conseguimos informações descrevendo tratamentos, cuidados, o medo da doença e os estigmas que tuberculosos e seus familiares sofriam.

Palavras-chave: Fase Sanatorial; Tratamento da Tuberculose; Cuidados em Saúde; História Oral.

\section{Abstract}

Research of qualitative nature that if considers to describe the performance of personages who took care of the patient inmates in the Vicentina Sanatorium Spider, at the beginning of the last century. The first sanatorium of Is Jose of the Fields was inaugurated in 1924, under the direction of the Brotherhood of the Saint Casa de Misericordia of São Paulo and received the name from Vicentina Spider. The present study it chose as research method, for collection and analysis of the data, verbal history. traverse of the interviews, we obtain information describing treatments, cares, the fear of the illness and the stigmata that tuberculosos and its familiar ones suffered.

Keywords: Sanatorial phase; Treatment of the Tuberculosis; Cares in Health; Verbal history. 


\section{Considerações Iniciais}

Na primeira metade do século XX tem início a Fase Sanatorial no município de São José dos Campos - SP, seguindo a tendência de medicalização dos diversos espaços urbanos que vinha se destacando desde o século XVIII.

A cidade de São José dos Campos está situada a 660 metros do nível do mar, com temperaturas anuais médias de 15 e 20 graus centígrados e quase equidistante da Capital, das praias do Litoral Norte e das montanhas de Campos de Jordão e cidades do sul de Minas Gerais, todas localizadas num raio de, aproximadamente, 90 quilômetros.

Os sanatórios eram edificações hospitalares, criadas e mantidas, principalmente, por ordens religiosas e que ofereciam aos pacientes algum amparo médico e assistência filantrópica.

Para Bittencourt (1998, p. 36), os sanatórios fazem parte da história da evolução das instituições hospitalares e dos estabelecimentos destinados ao isolamento de enfermos, sendo considerados precursores na introdução de novos sistemas de higiene, disciplina e do controle social.

O período sanatorial marcará toda a organização espacial e social de São José dos Campos, com a introdução de novas profilaxias e meios de tratamento dos doentes tuberculosos. Na época houve um grande fluxo migratório de tuberculosos, vindos, principalmente, de cidades como São Paulo e Rio de Janeiro. Os doentes se dirigiam para lá por conta da crença sobre propriedades terapêuticas do clima da cidade e uma possível cura, o que a faria conhecida como “Cidade Esperança”. Diante da ausência de drogas curativas na época, restava à medicina a exposição a determinados climas como recurso de tratamento dos enfermos.

Os sanatórios, utilizados como promissora tentativa de cura dos tuberculosos, partilhavam de princípios como a mudança do clima e a exposição do doente a uma região de ar puro, sendo a higiene, tanto do local quanto do paciente, principal aliada no tratamento da doença.

A Inglaterra foi o berço da concepção segundo a qual a doença poderia ser limitada por meio da atuação dos sanatórios, isso em 1854, quando o número de doentes e de óbitos causados pela chamada "Peste Branca", crescia de forma alarmante.

Segundo Foucault (1986:107), no fim do século XVIII, mecanismos disciplinares como o controle, o registro e o isolamento do doente no espaço do hospital criam a medicalização dos espaços que podem ser entendidos como "o preço atribuído ao desejo de evitar que as doenças se propagassem".

No Brasil, o tratamento da tuberculose não esteve desvinculado da concepção adotada pelo governo a respeito da saúde pública, ou seja, da política de saúde da época.

Apesar de proposta encaminhada ao Congresso Nacional, em 1907, pelo médico e diretor-geral do Departamento Nacional de Saúde, Oswaldo Cruz, sobre a aprovação de uma lei que estabelecia a obrigatoriedade clínica de notificação dos casos de tuberculose e a criação de um serviço especializado na enfermidade, o projeto foi rejeitado.

Foi o Estado de São Paulo que iniciou a primeira campanha nacional contra a tuberculose, tendo à frente o higienista Emílio Ribas, então diretor do Serviço Sanitário estadual entre os anos de 1898 e 1917, além do clínico carioca Clemente Miguel da Cunha Ferreira.

O doutor Clemente Ferreira, paralelamente às suas atividades como "médico de crianças", foi o responsável por organizar junto com o Serviço Sanitário Paulista, a Associação Paulista de Sanatórios Populares para Tuberculosos. Ele presidiu a instituição no período de 1899 até 1945 e, a partir de 1902, passou a ser chamada de Liga Paulista Contra a Tuberculose ${ }^{1}$, adotando os serviços dos dispensários, como principal eixo da assistência aos infectados.

Segundo Ribeiro (1993), a ação da Liga

(...) restringiu-se à propaganda, à confecção de cartazes, avisos, instruções populares com noções básicas de higiene, e ao apelo junto aos poderes públicos, às companhias de estradas de ferro e às gerências de fábricas e oficinas para que ajudassem na divulgação na execução de medidas profiláticas² [...] (RIBEIRO, 1993:126).

1 A primeira experiência no continente americano em criar uma Liga para a luta contra a tuberculose se deu na cidade de Santiago de Cuba, em 1890. A segunda foi exatamente a Liga Paulista, em 1899.

2 "proibição de escarrar no chão e no soalho de estabelecimentos públicos e locais com concentração humana”; "adoção de escarradeiras com líquido anti-séptico", "varredura úmida dos locais públicos e das fábricas e oficinas"; "vagões próprios para tuberculosos", "exame clínico do pessoal operário nas fábricas e afastamento dos operários com tuberculose aberta" e "adoção de escarradeiras de bolso para tuberculosos” (Revista Médica de São Paulo, São Paulo, ano V, n.3, p. 41-9, 1902, APUD RIBEIRO,1993:126. 
Com o apoio de outros colaboradores e auxiliado por uma subvenção municipal, o doutor Clemente Ferreira conseguiu abrir, em São Paulo, o primeiro dispensário para o tratamento e profilaxia das moléstias pulmonares, localizado à Rua Libero Badaró e inaugurado em 1904.

O primeiro sanatório de São José dos Campos foi inaugurado em 1924, sob a direção da Irmandade da Santa Casa de Misericórdia de São Paulo, recebendo o nome de Vicentina Aranha, esposa do Senador Olavo Egídio.

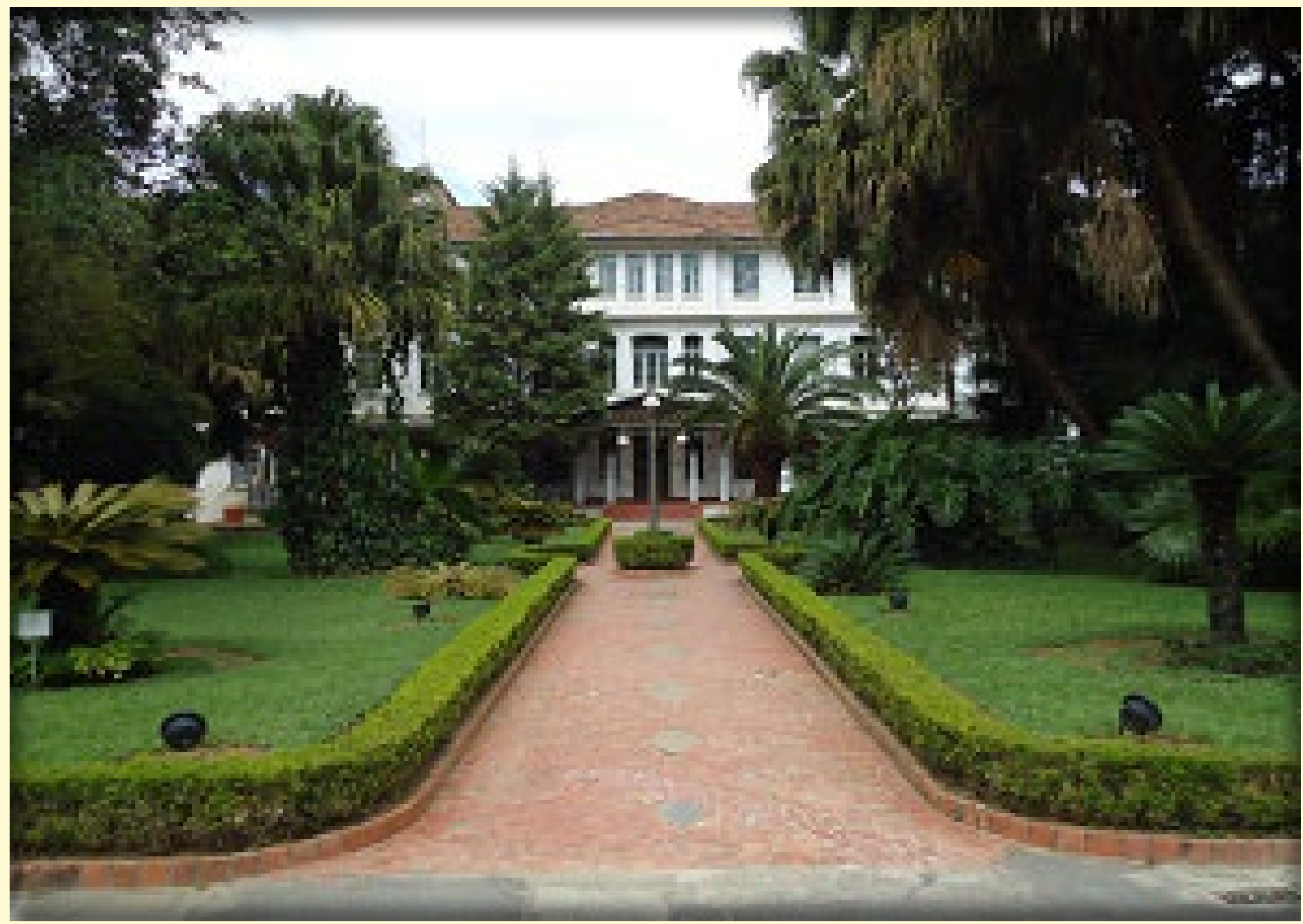

Foto: Lúcia Pedroso da Cruz

Em 1914, uma doação feita pela Câmara Municipal de São Paulo permitiu que a Irmandade da Santa Casa de Misericórdia adquirisse uma chácara na cidade de São José dos Campos, escolhida, conforme comentário anterior, devido ao clima considerado ideal para o tratamento da doença e por oferecer as condições de infraestrutura necessárias.

A obra foi projetada pelo arquiteto Francisco de Paula Ramos de Azevedo, um dos arquitetos mais importantes do Brasil, na época. A distribuição dos ambientes, isolados e independentes, permitia uma inspeção sempre zelosa e imediata dos pavilhões, realizada pelas freiras e funcionários.

O Vicentina Aranha foi constituído por mais de um edifício, o que fez dele um sanatório do tipo pavilhonar $^{3}$, formando um conjunto arquitetônico, onde cada edificação justificava-se simultaneamente, como abrigo para uma atividade específica, mas integrando um sistema maior.

O desenvolvimento de áreas e edifícios especialmente destinados à saúde, segundo Miquelin (1992), parece estar intimamente relacionado à evolução da prática médica, entretanto, a forma das construções está relacionada ao desenvolvimento das técnicas de engenharia e arquitetura, bem como às modificações estéticas dos diversos períodos históricos.

O complexo do Sanatório Vicentina Aranha está distribuído em um terreno que, na época da inau-

3 O modelo do tipo pavilhonar surgiu no século XVIII e durou até finais do século XIX. Caracterizou- se por uma série edificações isoladas as quais tinham funções específicas (BITTENCOURT, 1998). 
guração, ocupava uma área de 488.000 metros quadrados $\left(\mathrm{m}^{2}\right)$. Seus limites iniciavam-se na Rua Engenheiro Prudente Meireles de Moraes, que corresponde à parte frontal até os dias de hoje, descendo as laterais pelas avenidas São João e Nove de Julho até atingir as margens do Ribeirão Vidoca, atualmente os bairros Jardim Apollo e Vila Ema.

Grande parte da área ocupada originalmente pelo sanatório foi loteada para fins habitacionais na década de 1970, dando origem a bairros residenciais.

Atualmente, a área do antigo Sanatório Vicentina Aranha é de $84.500 \mathrm{~m}^{2}$, abrigando importante espaço cultural e de lazer ${ }^{4}$. Nesta área estão distribuídas 15 edificações existentes, sendo elas: Pavilhão São João $998.93 \mathrm{~m}^{2}$, Pavilhão São José - $1178.62 \mathrm{~m}^{2}$, Pavilhão Central $3775.35 \mathrm{~m}^{2}$, Pavilhão Mariana Crespi - $403.62 \mathrm{~m}^{2}$, Refeitório $1056.53 \mathrm{~m}^{2}$, Pavilhão Alfredo Galvão $181.30 \mathrm{~m}^{2}$, Pavilhão Paulista $827.58 \mathrm{~m}^{2}$, Lavanderia - 520.45 $\mathrm{m}^{2}$, Caldeira $376.88 \mathrm{~m}^{2}$, Laboratório - $167.80 \mathrm{~m}^{2}$, Manutenção $360.52 \mathrm{~m}^{2}$, Necrotério $56.44 \mathrm{~m}^{2}$, Portaria 105.26 $\mathrm{m}^{2}$, Capela $339.71 \mathrm{~m}^{2}$, Gruta $-34.60 \mathrm{~m}^{2}$. Além das edificações, o sanatório é circundado por um bosque com área de 43.887,90 $\mathrm{m}^{2}$, separados em canteiros com paisagismo e canteiros com bosque, contendo ainda algumas espécies raras e centenárias como: mogno, peroba-rosa, jequitibá, jacarandá da Bahia, Jatobá, Cabreúba Vermelha, Louro Pardo e outros 5 .

As técnicas utilizadas para a construção do Vicentina Aranha foram: para a vedação, alvenaria de tijolos maciços, com paredes que chegam a 0,30 $\mathrm{m}$ de espessura, todas embocadas, rebocadas e pintadas, tendo barra impermeável em tinta a óleo ou azulejo branco nas áreas úmidas. A cobertura, feita com telhas do tipo francesa, repousa sobre estrutura de madeira. As galerias, ligando os diferentes edifícios, não tem vedação lateral e, na cobertura, em duas águas, usou-se madeira aparelhada para dispensar forros e demais revestimentos. Os forros são executados, geralmente, com estuque de gesso francês, sendo que o encontro com as paredes é arredondado por razões assépticas. (Ver Nota de rodapé no 5 ).

A ventilação e a entrada dos raios solares nas instalações, propriedades consideradas terapêuticas, são particularidades do projeto que conferiram ao sanatório as melhores condições para o tratamento da doença.

A cozinha também merece destaque dentro de um sistema sanatorial porque para o tratamento da tuberculose, além do repouso e do isolamento, a boa alimentação é aspecto fundamental.

Este conjunto arquitetônico é amplamente reconhecido pela comunidade como um dos mais importantes da fase sanatorial. Além disso, a construção é uma referência das primeiras manifestações da modernidade no Vale do Paraíba.

Apesar da grande procura para o tratamento de tuberculose pulmonar em São José dos Campos, foi somente em 1935, quando o município foi transformado em Estância Climática e depois Estância Hidromineral, que a cidade passou a receber recursos oficiais que puderam ser aplicados na área sanatorial.

Vianna e Ribeiro (2011) explicam que:

Nesse espaço dinâmico, as políticas nacionais ganham vida e são modificadas, criam-se novas proposições e possibilidades para a consecução de fins não visualizados inicialmente: em São José dos Campos, a tuberculose foi o motriz para a entrada do município no circuito modernizador paulista, por mais antagônica que essa relação possa parecer a princípio (VIANNA; RIBEIRO,2011:259).

Outra mudança, São José dos Campos passou a ter prefeitos nomeados, chamados de "prefeitos sanitaristas”. Apenas em 1977, pela lei estadual, a cidade pode voltar a eleger seus prefeitos, sendo que a primeira eleição para prefeito, se deu, então, em 15 de novembro de 1978.

A cidade de São José dos Campos contou com diversos sanatórios, dentre os quais se sobressaíram $\mathrm{O}$ Vicentina Aranha, pertencente à Santa Casa de São Paulo, inaugurado em 1924, pelo presidente de São Paulo Dr. Washington Luís; o Vila Samaritana, pertencente à comunidade evangélica; o Ezra, pertencente à comunidade judaica, o Maria Imaculada e o Sanatório Antoninho da Rocha Marmo, pertencentes à Igreja Católica; o Ruy Dória, criado

4 O Vicentina Aranha foi tombado pelo CONDEPHAAT - Conselho de Defesa do Patrimônio Histórico, Arqueológico, Artístico e Turístico - em janeiro de 2001, tornando-se patrimônio do estado. Posteriormente, em 2004, a Irmandade da Santa Casa de Misericórdia encerrou as suas atividades. Atendendo ao desejo da população de ver o Vicentina Aranha preservado, em 2006 a Prefeitura de São José dos Campos comprou a propriedade e o reabriu, no ano seguinte, como Parque Cultural Vicentina Aranha.

5 Fonte: HTTP://www.fccr.org.br/index.php?option=com_content\&view=section\&id=21\&Itemid=157 Acesso em 2/6/2013 
e pertencente ao médico Dr. Ruy Rodrigues Dória; e o Sanatório Ademar de Barros, criado pelo governador Dr. Adhemar Pereira de Barros e dirigido e mantido pela "Liga de Assistência Social". Existiu também na Rua Paraibuna, o Sanatório São José, do doutor Jorge Zarur.

Em 1941, foi criado o Serviço Nacional de Tuberculose e entre seus objetivos estavam os de disseminar programas de prevenção à doença no país e construir sanatórios e dispensários. Os primeiros atendiam, em geral, doentes dotados de condições para pagar seu tratamento. O outro tipo de instituição, mantida com verba pública, servia a população carente (VIANNA; RIBEIRO, 2011).

Cesco (1992), em seu estudo, salienta que o município, durante a fase sanatorial, passou a receber todos os tipos de pessoas como médicos, doentes, poetas, escritores, padres, freiras, pobres e indigentes.

Como médicos sanitaristas, destacaram-se na região, principalmente: Ruy Dória,

Jorge Zarur, Orlando Campos, João Batista de Souza Soares, Ivan de Souza Lopes, Décio Lemes Campos, Amaury Louzada Velozo e Nelson Silveira D’Avila.

Muitos dos doentes que não conseguiam vagas nos sanatórios ou sem recursos para pagar pelo tratamento oferecido em tais instituições, hospedavam-se naquelas pensões que aceitavam pessoas enfermas.

\section{Percurso da Pesquisa}

Com base nestas considerações iniciais, o presente artigo teve como objetivo conhecer a atuação de personagens que executavam cuidados aos pacientes portadores de tuberculose, bem como quais os cuidados prestados aos doentes, reclusos no Sanatório Vicentina Aranha, no início do século passado.

Para isto, elegemos como método de pesquisa, para coleta e análise dos dados, a história oral. Compondo a amostra do estudo, foram encontradas duas funcionárias que atuaram no cuidado ao paciente portador de tuberculose no Vale do Paraíba Paulista.

Entre os autores do campo da história que servem de suporte teórico para este trabalho estão aqueles que propuseram nova maneira de "se fazer história", isto é, construir uma história questionadora - a "história-problema" - sem respostas definitivas, em oposição à produção uma história real, objetiva e acabada, com um encadeamento linear de causas e efeitos. Os historiadores adeptos da Escola dos Annales valorizam, em suas investigações, a história do homem comum, do operário, da mulher, da familia. Ampliaram a noção de documento, considerando que a fonte escrita não é a única possibilidade de resquício da ação humana a ser utilizada pelo pesquisador. Para Marc Bloch, qualquer documento tem uma intenção e anunciá-la faz parte da análise inescapável do pesquisador que trabalha sob a perspectiva do campo da História. Diante da impossibilidade de se colocar no passado, o pesquisador precisa se perguntar qual a rede de relações em que determinado testemunho está inserido. Isto é, um testemunho é sempre uma perspectiva e, como tal, precisa ser analisado nas intenções do sujeito (BLOCH, 2001).

Le Goff acrescenta que "devemos fazer o inventário do silêncio e fazer a história a partir dos documentos e da ausência de documentos” (LE GOFF, 2005:109).

Outro historiador, Carlo Ginzburg (2006), em seu trabalho intitulado O queijo e os vermes, propõe uma ampla reflexão sobre os desafios, as barreiras e as possibilidades na escrita da história, ou melhor, história(s) - porque, em seu entender, cabe ao historiador revelar verdades possíveis sobre homens do passado, fazendo a leitura das fontes a contrapelo ou às avessas, como sugere Marc Bloch.

Ginzburg não trabalhou com o conceito de certo ou errado; não quis julgar, e sim interpretar as razões que fizeram com que o protagonista da pesquisa agisse da forma como o fez. Tal proposta serve de alerta, portanto, quando são utilizados como fontes, depoimentos e narrativas de pessoas envolvidas em determinado momento que o pesquisador se dispõe a estudar.

Mais uma vez lembrando Bloch (2001): "O historiador não observa diretamente os fatos que estuda". "Das épocas que estudamos, só podemos falar a partir de testemunhas” (Bloch, 2001:69). O conhecimento ocorre por meio de vestígios, pois os fatos não pululam das fontes. É preciso, portanto, saber interrogar os documentos; fazê-los falar. Para isso, é fundamental que se amplie o conceito de fontes (não se limitando apenas àquelas escritas e em documentos oficiais). Qualquer tipo de vestígio da atividade humana pode servir como elemento capaz de informar a respeito da experiência humana.

6 A revista ANNALES foi fundada por Marc Bloch e Lucien Febvre na França, em 1929, apresentando inovações marcantes nos estudos do campo da história. 
Peter Burke (1992) chama a atenção para que temas relativos a alimentação, vestuário, vida privada, loucura, mulheres, negros, entre outros sejam retomados sob a ótica de que toda em toda produção humana e em cada tipo de ser humano existe uma história a ser desvelada e compreendida.

Padilha e Borenstein (2006) lembram que:

A pesquisa histórica tem o propósito de demonstrar os sucessos, fracassos, ocorrências em geral ou eventos no âmbito de interesse do historiador [...] O conhecimento que se procura por meio da investigação histórica depende inteiramente da informação que tenha sido transmitida ao longo do tempo por aqueles que viveram o evento ou assunto que se investiga em lugar e tempo apropriado (PADILHA; BORENSTEIN, 2006:577).

Diante da ampliação do conceito de história e de fontes históricas, o advento do gravador trouxe uma nova possibilidade de se obter testemunhos, por meio de entrevistas registradas com o novo aparelho. Assim, a história oral é uma metodologia que "consiste em realizar entrevistas gravadas com pessoas que podem testemunhar sobre acontecimentos, conjunturas, instituições, modos de vida ou outros aspectos da história contemporânea ."

Foi trazida ao Brasil nos anos de 1970 e, nesta ocasião, foi criado o Programa de História Oral do Centro de Pesquisa e Documentação de História Contemporânea do Brasil (CPDOC), que é a Escola de Ciências Sociais da Fundação Getúlio Vargas. E Meihy (2000), acrescenta:

Pode-se dizer que a moderna história oral brasileira definiu-se entre nós a partir de 1979, florescendo principalmente depois de 1983 no processo de redemocratização política do País. Ainda que houvesse um esforço anterior, nos anos 70, como prática assumida com vigor, somente depois de um amadurecimento que implicou aproximação de diferentes tendências foi que se afinaram os debates capazes de promover espaços coletivos para a combinação de opiniões (MEIHY, 2000:89).

A história oral possibilita a construção e a reconstituição da história por meio dos relatos individuais ou coletivos.

[...] o maior desafio da história oral [...] é contribuir para que as lembranças continuem vivas e atualizadas, não se transformando em exaltação ou crítica pura e simples do que passou, mas sim em meio de vida, em procura permanente de escombros, que possam contribuir para estimular e reativar o diálogo do presente com o passado (NEVES, 2003:29).

Ronald J. Grele (2001) e Guita G. Debert (2001) explicam sobre a importância da história oral como método de pesquisa, pois, segundo o autor, ela possibilita reconstruções históricas por meio de informações não documentadas, histórias ocultas, inclusive daqueles seres humanos oprimidos ou excluídos ou dados que possam contribuir para a compreensão de cotidianos da vida doméstica, de relações pessoais ou ainda sobre organizações clandestinas.

E nas palavras de Philippe Joutard (2000):

A força da história oral, todos sabemos, é dar voz àqueles que normalmente não a têm: os esquecidos, os excluídos ou, retomando a bela expressão de um pioneiro da história oral, Nuno Revelli, os "derrotados". Que ela continue a fazê-lo amplamente, mostrando que cada indivíduo é ator da história. [...]É através do oral que se pode apreender com mais clareza as verdadeiras razões de uma decisão; que se descobre o valor de malhas tão eficientes quanto as estruturas oficialmente reconhecidas e visíveis; que se penetra no mundo do imaginário e do simbólico, que é tanto motor e criador da história quanto o universo racional (JOUTARD, 2000: 33-34).

Durante as entrevistas, as falas revelaram o cotidiano do Sanatório Vicentina Aranha, principalmente no que diz respeito aos cuidados prestados, sendo estes determinados pela classe social; ao controle exercido pelas freiras, nos espaços e nas pessoas envolvidas com os cuidados; aos escassos recursos terapêuticos da época e ao estigma da doença.

A pesquisa com a metodologia de história oral compreende todo um conjunto de atividades anteriores e posteriores à gravação dos depoimentos. É necessário, anteriormente, a compreensão do contexto da pesquisa e o levantamento de dados para a preparação do roteiro da entrevista. Por outro lado, foi primordial levar em

7 Fonte: <http://cpdoc.fgv.br/acervo/historiaoral>. Acesso em 05/06/2013. 
conta a idade e a disposição das entrevistadas para narrar sobre particularidades de uma etapa de suas vidas. Iniciamos a entrevista com a seguinte questão: Fale sobre sua atuação no cuidado ao portador de tuberculose no início do século passado, no Sanatório Vicentina Aranha. Perguntas iam sendo propostas, na medida em que a pessoa oferecia espaços para que fossem solicitados complementos para as informações.

A este respeito, Alister Thomson trouxe o aporte, quando colocou em discussão a "maneira certa" de se conduzir uma entrevista, argumentando:

(...) os historiadores orais vieram a perceber, nos últimos anos, o fato crucial - derivado, em parte, da antropologia e de estudos sobre as comunicações e promovido por pesquisadoras feministas - de que a entrevista é uma relação que se insere em práticas culturais particulares e que é informada por relações e sistemas de comunicação específicos. Em outras palavras, não existe uma única "maneira certa" de entrevistar, e a maneira que o "bom senso" indica como "certa" para entrevistas com membros da elite política branca do sexo masculino pode ser completamente inadequada em outros contextos culturais (THOMSON, 2000:48).

\section{Tuberculose: Histórias Pessoais e Familiares}

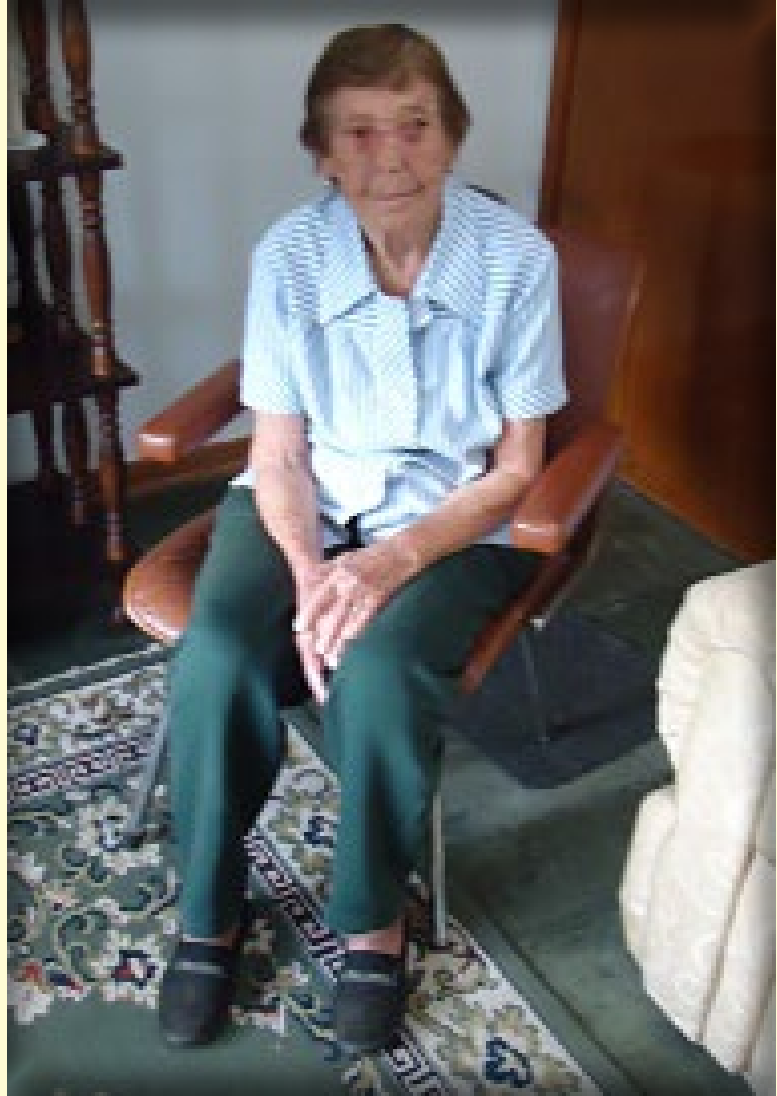

Foto: Lúcia Pedroso da Cruz

Dona Dolores ${ }^{8}$, uma de nossas entrevistadas, aos 98 anos e com muita lucidez, nos recebeu carinhosamente e aceitou falar sobre sua vida e sobre os anos de trabalho junto as doentes do Vicentina Aranha, indicando também, um possível segundo nome para a outra entrevista que acabamos também realizando.

Aos 17 anos, Dona Dolores deixaria de ser uma trabalhadora rural, da fazenda Jacira, no município de Santa Branca/ SP, para se tornar uma cuidadora' no Sanatório Vicentina Aranha. A opção foi forçada por razões econômicas, ainda que o novo salário também fosse baixo e os riscos para a saúde, talvez, não muito conhecidos pela jovem trabalhadora.

Observamos nos relatos das duas entrevistadas que era comum as pessoas que já trabalhavam no sanatório indicarem futuros funcionários, quando isso era preciso. Sempre no âmbito da própria família, os indicados e admitidos tinham pouco ou nenhum estudo, aceitavam baixa remuneração e raras folgas, além da vantagem do conhecimento das normas pelo contato com o parente.

A rotina começava bem cedo para os funcionários. Primeiro, a missa diária e só após, o café da manhã. O uniforme, lavado e passado na lavanderia da própria instituição, era composto de avental, gorro e um tipo de alpargatas.

A moça baixa e franzina era responsável por atender seis quartos do longo corredor, localizado na ala superior e destinado apenas a mulheres que tinham condições de pagar pelo tratamento, o qual, para a realidade da época, era considerado diferenciado.

Quando o sino tocava era o momento de ação: ou a paciente precisava de algo, ou um dos médicos adentrara o portão principal. No primeiro caso, a orientação era clara: seria necessário respirar fundo, prender o ar e entrar no quarto para execução de rápido e preciso cuidado, que poderia ser, por exemplo, ajudar a paciente a sentar no leito ou na poltrona localizada ao lado da cama. Em outro momento, a colocação de bolsa de água quente nos pés traria conforto térmico e relaxamento para a doente.

As pacientes da ala superior recebiam várias refeições por dia e diversos tipos de caldos, servidos bem aquecidos. Como não havia nenhum tipo de comunicação com os pacientes das alas destinadas aos indigentes e com os que ali trabalhavam, esta nossa entrevistada desconhece as rotinas dos espaços diferentes aos de sua atuação.

8 Dolores de Godoy Quintino, nascida em Santa Branca em setembro de 1914.

9 O termo cuidadora está sendo utilizado por opção das autoras e define atitude zelosa e de cuidado. 
Ainda no quarto, a lavagem das mãos deveria ser realizada na pequena pia existente para esta finalidade. Com a saída do recinto, vinha o alívio por poder restabelecer a respiração normal.

Na segunda possibilidade, para o badalar do sino, Dr. Nelson D’Ávila ou Dr. Soares haviam chegado para as consultas médicas. Então, o silêncio deveria ser absoluto. A jovem cuidadora fora orientada a permanecer sentada no corredor, de cabeça baixa, sem conversar com as outras, igualmente, jovens cuidadoras. Os médicos examinariam as pacientes e trocariam informações, apenas, com as freiras. Estas sim acompanhavam as visitas, liam e escreviam nos prontuários e poderiam livremente se dirigir às autoridades médicas.

Poucas doentes recebiam visitas e, com o avançar do tempo de internação, elas se tornavam mais raras. A única companhia constante das pacientes, sempre isoladas em quartos individuais, era o rádio, que deveria estar com som baixo e sempre desligado diante da presença do médico.

O tempo livre das cuidadoras era preenchido por leituras, exclusivamente, religiosas, para as que sabiam ler e por trabalhos manuais simples, do tipo crochê e tricô.

O merecido repouso, conta Dona Dolores, era realizado em quarto compartilhado com outras cinco moças que tinham a mesma atuação no sanatório e com uma freira, sempre vigilante e que não seria condescendente com nenhuma postura não condizente com a seriedade esperada para o ambiente.

$\mathrm{Na}$ memória e na conversa dessa simpática senhora, ainda hoje, surgem nomes de alguns personagens e suas respectivas ocupações no Sanatório: Dona Cotinha era responsável pelos cuidados aos mortos; a Irmã Caetana cuidava do refeitório; Irmã Paula e Irmã Ida tomavam conta da ala superior...

O nome da doença não é pronunciado por Dona Dolores, que do mesmo modo, não admite que contraiu tuberculose, sendo detectada a cicatriz pulmonar, segundo seus familiares, há tempos atrás.

Percebemos que os sinais e sintomas que afloravam do corpo das pacientes, permanecem na memória da nossa entrevistada. Porém, ela foge o quanto pode do assunto, preferindo falar detalhes do seu trabalho. As hemoptises e dispneias vêm à tona quando Dona Dolores, emocionada, se permite falar de uma jovem que morreu em seus braços, durante a execução de um cuidado.

Ao lidarmos com a memória como campo de disputas e instrumento de poder, ao explorarmos modos como memória e história se cruzam e interagem nas problemáticas sociais sobre as quais nos debruçamos, vamos observando como memórias se instituem e circulam, como são apropriadas e se transformam na experiência social vivida. No exercício da investigação histórica por meio do diálogo com pessoas, observamos, de maneira especial, modos como lidam com o passado e como este continua a interpelar o presente enquanto valores e referências (KHOURY, 2004: 116-138).

A nossa segunda entrevistada, uma senhora de 72 anos, recebeu o nome de Vicentina ${ }^{10}$ em homenagem ao Sanatório, local de trabalho de sua mãe, Dona Florípedes Rodrigues, que ali prestou serviços até a aposentadoria.

A própria Vicentina também teve uma rápida passagem pelo sanatório como trabalhadora, porém, não entra em detalhes sobre os quatro meses como funcionária.

Dona Florípedes já faleceu. Trabalhava na lavanderia e conhecia boa parte das cuidadoras e das freiras, já que, independente da ala de trabalho, era na lavanderia que as cuidadoras iam buscar roupas de cama e banho limpas e passadas. As roupas eram sempre entregues em grandes cestos, carregados por duas cuidadoras e supervisionados pelas religiosas.

Sua avó, conta Dona Vicentina, trabalhou e morreu no sanatório. Ela também teve outros parentes que trabalharam no Vicentina Aranha, o que corrobora o que já mencionamos sobre os familiares indicarem uns aos outros para as vagas disponíveis na instituição.

\section{Comentários Finais}

A falta de maior conhecimento sobre a doença na época fazia com que se criasse uma relação entre a enfermidade e crenças não consideradas científicas. Assim, o estigma emerge sobre as vítimas da tuberculose e se acreditava que a melhor solução para o problema era retirar os doentes do convívio de familiares, amigos, vizinhos, sendo, portanto, o isolamento o único caminho.

A história oral, como mais que um fértil recurso para o tipo de pesquisa aqui apresentada, representou oportunidade ímpar de contato com pessoas que nos trouxeram informações importantes, como os cuida-

10 Vicentina de Paula Godói, nascida em São José dos Campos, em 21 de dezembro de 1941. 
dos utilizados na época, os principais tratamentos, o medo da doença, que era vista como uma sentença de morte além dos estigmas que os tuberculosos e seus familiares sofriam.

Os nossos agradecimentos a nossas entrevistadas e a seus familiares, que, por meio das falas, deixaram aflorar lembranças, registros, observações, silêncios, emoções e reflexões que nos fizeram, também como ouvintes, viajar através da história narrada.

\section{Referências bibliográficas}

BITTENCOURT, T. M.M. 1998. Arquitetura Sanatorial. São José dos Campos, Unidades Gráficas e Editora Ltda.

BLOCH, M. 2001. Ofício de historiador (ou Apologia da História). Rio de Janeiro: Jorge Zahar.

BURKE, P. (organizador). 1992. A escrita da história: novas perspectivas. Tradução de Magda Lopes. São Paulo: Ed. Unesp.

1990. A escola dos Annales (1929- 1989): a revolução francesa da historiografia. Tradução de ODALIA N. , São Paulo: Ed. Unesp.

CESCO, N. de T. 1992. São José dos Campos: uma visão sanatorial. 1 ed. São José dos Campos: Fundação Cultural Cassiano Ricardo.

DEBERT, G. G. 2001. Problemas relativos à utilização da história oral de vida e história oral. In: AMADO, J.; FERREIRA, M.M. Usos \& abusos da história oral. 4. ed. Rio de Janeiro: FGV. 304 p.

FERREIRA, M.M.; FERNANDES, T.M.; A., V. (org.). 2000. História oral: desafios para o século XXI. Rio de Janeiro: FIOCRUZ. 204 p.

FOUCAULT, M. 1986. Microfísica do poder. Organização, introdução e tradução de MACHADO R. Ged. Rio de Janeiro: Graal.

GINZBURG, C. 2006. O queijo e os vermes: o cotidiano e as ideias de um moleiro perseguido pela Inquisição. São Paulo: Companhia das Letras.

GRELE, R. J. 2001. Pode-se confiar em alguém com mais de 30 anos? Uma crítica construtiva a história oral. In: AMADO, J. FERREIRA, M. M. In: Usos \& abusos da história oral. 4 ed. Rio de Janeiro: FGV. cap. 4 , p. 267-277.

JOUTARD, P. 2000. Desafios à história oral do século XXI. In: ALBERTI, V.; FERNANDES, T.M.; FERREIRA, MM. (Orgs.) História oral: desafios para o século XXI [online]. Rio de Janeiro: Editora Fiocruz. 204p.

KHOURY, Y. 2004. Muitas memórias, outras histórias: cultura e o sujeito na História. In: FENELON, D.; MACIEL, L.; A., P. e KHOURY, Y. (Orgs.). Muitas Memórias, Outras Histórias. São Paulo: Olho d'Água. p. 116-138.

LE GOFF, J. 2005. História e memória. Campinas, SP: UNICAMP.

MEIHY, J. C. S. B. 2000. Desafios da História Oral Latino-Americana: o caso do Brasil. In: ALBERTI, V.; FERNANDES, T.M.; FERREIRA, MM. (Orgs.) História oral: desafios para o século XXI [online]. Rio de Janeiro: Editora Fiocruz. 204p.

MIQUELIN, L.C. 1992. Anatomia dos edifícios hospitalares. São Paulo: Cedas.

NEVES, L. A. 2003. Memória e história: potencialidades da história oral. Uberlândia: ArtCultura, nº 6, 27-38.

PADILHA, M. I. C. de S.; BORENSTEIN, M. S. 2005. O método de pesquisa histórica na enfermagem. Texto \& Contexto Enfermagem, Florianópolis. 14(4):575-84. 
Artigos

RIBEIRO, M. A. R. 1993. História sem fim... Inventário da Saúde Pública. São Paulo - 1880-1930. São Paulo: Editora da UNESP.

SIMSON, O. R. de M. V. 2000. Memória, cultura e poder na sociedade do esquecimento: O exemplo do centro de memória da UNICAMP. In: Faria Filho, L. M. de (org.). Arquivos, Fontes e Novas Tecnologias: questões para a bistória da educação. Campinas, SP: Autores Associados, Bragança Paulista, SP: Universidade São Francisco.

VIANNA, P. V. C.; RIBEIRO, F. A. 2011. Sanatórios, tecnologia médica e cultura urbana: uma visita à cidade sanatorial de São José dos Campos na primeira metade do século XX. In: MOTA, A.; MARINHO, G. S .M. C. Práticas médicas e de saúde nos municípios paulistas: a história e suas interfaces.São Paulo: USP, Faculdade de Medicina: CD.G Casa de Soluções e Editora.

\section{Referências eletrônicas}

www.fccr.org.br/comphac/vicentina.htm. Acesso em 12/05/2013.

http://www.fccr.org.br/index.php?option=com_content\&view=section\&id=21\&Itemid=157. Acesso em $02 / 06 / 2013$.

<http://cpdoc.fgv.br/acervo/historiaoral>. Acesso em 05/06/2013 